\title{
Comparative Analysis of Clinical and Laboratory Parameters of Autoimmune and Idiopathic Chronic Urticaria Patients
}

\author{
Đuka Ninković Baroš,, 2 Vesna Gajanin,, ${ }^{1}$ Bogdan Zrnić, ${ }^{2}$ Živorad Gajanin,, 3 \\ Gordana Katalina ${ }^{1,2}$
}

\section{Abstract}

Background: According to the cause, chronic urticaria is most frequently divided into autoimmune and idiopathic urticaria. Aim of the paper was to determine the frequency of autoimmune urticaria using autologous serum skin testing and a comparative analysis of chronic idiopathic and chronic autoimmune urticaria by disease course, severity and most common comorbidities.

Methods: Analysis covered 64 adult patients of both sexes with chronic urticaria, divided into two groups according to their positivity in autologous serum skin testing (group I with positive test and group II with negative test). General haematological and biochemical parameters, antithyroid antibodies, hepatitis serum markers, Helicobacter pylori and Borrelia burgdorferi antibodies were performed for patients in both groups. First group patients were treated by autologous blood therapy (autohaemotherapy). The analytical statistical tool SPSS (Statistical Product and Service Solutions) version 20 for descriptive statistics and statistical methods was used. The significance level used was $p=0.05$.

Results: The frequency of positive autologous serum test in total population of patients with chronic urticaria was $43.8 \%$. The average duration of urticaria was 20 months in both groups. Statistically significant difference was found in weekly scores between the studied groups $(p=0.032)$ in favour of chronic autoimmune urticaria with a positive autologous serum test. Subjects with chronic autoimmune urticaria had a significantly higher association with autoimmune thyroid diseases.

Conclusions: Direct relation was established between the use of autologous blood therapy in patients with autoimmune chronic urticaria and improvement of the clinical picture.

Key words: Autologous serum skin test; Autoimmune chronic urticaria; Idiopathic chronic urticaria.

\section{Introduction}

Urticaria is manifested by the appearance of erythematous, oedematous, usually pruritic urticarial papules and plaques, accompanied by a subjective itching sensation. ${ }^{1}$ Urticaria affects persons of all ages. One in five persons will experience episodes of acute urticaria at least once in their lifetime, while the chronic form of the disease has an estimated annual prevalence of about $1 \%$. Fre- quency of urticaria in the world ranges between 0.3 and $11.3 \%$ depending on the studied population. ${ }^{2}$ Zuberbier classified urticaria according to duration, frequency and cause into acute (AU) and chronic urticaria (CU).

AU implies changes lasting up to six weeks. CU is defined by the appearance of wheals on the skin

Copyright $\odot 2021$ Ninković Baroš et al. This is an open access article distributed under the Creative Commons Attribution License (CC BY), which permits unrestricted use, distribution, and reproduction in any medium, provided the original work is properly cited. This article should be cited as follows: Ninković Baroš Đ, Gajanin V, Zrnić B, Gajanin Ž, Katalina G. Comparative analysis of clinical and laboratory parameters of autoimmune and idiopathic chronic urticaria patients. Scr Med 2021 Dec;52(4):239-48. 
Table 1: Classification of urticaria according to duration, frequency and causes

\begin{tabular}{ll}
\hline Type of urticaria & \multicolumn{1}{c}{ Duration } \\
\hline Spontaneous urticaria & \\
\hline Acute urticaria & Less than six weeks \\
\hline Chronic urticaria & More than six weeks \\
\hline - unknown aetiology & \\
\hline Induced urticaria & (i) Application of mechanical forces to the skin \\
\hline & (wheals appear in 1 to 5 minutes) \\
(i) Dermographism & (ii) Vertical pressure (wheals appear after 3 to 8 hours of latency) \\
\hline (ii) Delayed pressure urticaria & (iii) Cold air/water/wind \\
\hline (iii) Urticaria secondary to cold & (iv) Localised heat \\
\hline (iv) Urticaria secondary to heat & (v) Ultraviolet (UV) and/or visible light \\
\hline (v) Solar urticaria & (vi) Vibratory forces, usually pneumatic devices \\
\hdashline (vi) Urticaria/vibratory angio- oedema & (vii) Contact with water, regardless of its temperature \\
\hline (vii) Aquagenic urticaria & (viii) Stress, perception of body temperature elevation by the hypothalamus \\
\hline (viii) Cholinergic urticaria & (ix) Allergic or pseudo-allergic \\
(ix) Contact urticaria &
\end{tabular}

and/or angioedema during a period longer than 6 weeks, most days of the week, for known or unknown reasons. CU comprises chronic spontaneous and chronic inducible urticaria (Table 1). The term physical urticaria has been revised into the term chronic inducible urticaria (CINDU) to indicate its physical trigger and inducible nature of urticaria and includes aquagenic, cholinergic and contact urticaria. Other forms of urticaria, which occur without an external trigger and via an endogenous mechanism are classified as chronic spontaneous urticaria (CSU). ${ }^{3,4}$ Possible causes of CU are medicines, food, infection, circulating immune complexes (CIC), autoantibodies in associated autoimmune disease, as in autoimmune thyroid disease and internal malignancy. ${ }^{5}$ The concept of urticaria as a systemic disease is confirmed by its association with other autoimmune diseases, most commonly Hashimoto's thyroiditis, and this association is one of the evidences of the autoimmune aetiology of urticaria (ACU), as a variant of CU. ${ }^{6}$ In most cases, it is an autoimmune disease caused by circulating functionally active IgG antibodies specific for the IgE receptors (FceRI) present on mast cells or basophils (35-40 \%) or antibodies to their own IgE (5 $-10 \%) .{ }^{7}$ Autoantibodies in ACU induce histamine release from mast cells and basophilic leukocytes directly via IgE receptors or IgE. Increased expression of Tumour Necrosis Factor- $\alpha$ (TNF- $\alpha$ ) in patients with CU plays a role in the occurrence of inflammatory response. The presence of a late inflammatory phase explains why CU patients do not respond to the usual therapy used in acute urticaria. $^{8-10}$

Urticaria management is based on the recommendations of the EAACI/GA2LEN/EDF/WAO guidelines (Guideline for the definition, classifi- cation, diagnosis and management of urticaria: the 2013 revision and update, published in 2014. . $^{11,12}$ Medical history can be considered the most valuable diagnostic 'tool' in identifying the cause of CU (Table 2). ${ }^{12,13} \mathrm{CU}$ diagnosis and evaluation are supplemented by urticaria severity score (USS) and the laboratory findings: antinuclear antibody titre (ANA), complement components C3, $\mathrm{C} 4$, thyroid function, antibodies to thyroglobulin and tissue peroxidase, which indicate association of urticaria with other autoimmune diseases. ${ }^{14-17}$ Diagnostic recommendations are presented in Table $3{ }^{3}$ The simplest test in the differential ACU diagnosis is the autologous serum test in the form of an ID test with $0.05 \mathrm{~mL}$ of autologous serum (ASST). A positive ASST test indicates the presence of antibodies to high-affinity receptors on mast cells and basophils and/or IgE. The ASST test is useful in differentiating between ACU and ICU. It was first described by Grattan et al in 1986, with high sensitivity (70 \%) and specificity (80\%), as well as by other authors. ${ }^{18-24}$

Lately, the basophil activation test is being used in the diagnosis of ACU. ${ }^{21}$ The European Panel on Allergic Diseases suggests scoring to assess

\section{Table 2: Anamnestic data in urticaria diagnosis}

1. Signs and symptoms associated with the onset of changes: itching/burning

2. Duration of individual change, occurrence of angio-oedema, other symptoms including fever, weight loss, abdominal pain,

joint pain

3. Trigger identification: new medication, such as antibiotic, NSAID, hormones

4. Aggravating factors, physical stimuli - heat, cold, alcohol, stress, food

5. Atopy

6. Medical history and changes in patient's health

${ }^{\star}$ Rule out other diseases by differential diagnosis 
Table 3: Recommended diagnostic tests in frequent urticaria subtypes (modified according to Zuberbier et al)

\begin{tabular}{|c|c|c|}
\hline Urticaria group/subtype & Routine diagnostic test & Extended diagnostic programme \\
\hline & Spontaneous urticaria & \\
\hline Acute urticaria & No & No \\
\hline \multirow[t]{2}{*}{ Chronic urticaria } & $\begin{array}{l}\text { Differential blood count (DBC), } \\
\text { C-reactive protein (CRP), } \\
\text { sedimentation (ESR), suspected } \\
\text { medicine (eg NSAIL) }\end{array}$ & $\begin{array}{l}\text { Potential infection (eg Helicobacter pylori) and type I } \\
\text { allergic reactions, antithyroid antibodies, thyroid hormones, } \\
\text { antinuclear antibodies (ANA) physical tests, pseudoallergen, } \\
\text { autologous serum skin test, serum tryptase, biopsy; }\end{array}$ \\
\hline & Chronic inducible urticaria & \\
\hline Acquired cold urticaria & $\begin{array}{l}\text { Cold provocation } \\
\text { (ice cube test, cold water, wind) }\end{array}$ & $\begin{array}{l}\text { DBC, ESR/CRP, cryoproteins, rule out other diseases, } \\
\text { especially infections. }\end{array}$ \\
\hline Pressure urticaria & $\begin{array}{l}\text { Pressure }\left(0.2-1.5 \mathrm{~kg} / \mathrm{cm}^{2} 10\right. \\
\text { and } 20 \mathrm{~min})\end{array}$ & No \\
\hline Heat urticaria & Heat provocation (warm water) & No \\
\hline Solar urticaria & $\begin{array}{l}\text { UV and visible light (different } \\
\text { wavelengths) }\end{array}$ & Rule out other light-induced dermatoses \\
\hline \multirow[t]{2}{*}{$\begin{array}{l}\text { Dermographism /urticaria } \\
\text { factitia }\end{array}$} & Elicit dermographism & DBC, ESR/CRP \\
\hline & Other urticarial diseases & \\
\hline Aquagenic urticaria & Wet compress on the skin $20 \mathrm{~min}$ & No \\
\hline Cholinergic urticaria & Exercise or warm bath & No \\
\hline Contact urticaria & $\begin{array}{l}\text { Prick epicutaneous/test } \\
\text { after } 20 \text { min }\end{array}$ & No \\
\hline $\begin{array}{l}\text { Exercise-induced urticaria/ } \\
\text { anaphylaxis }\end{array}$ & $\begin{array}{l}\text { According to anamnesis exercise } \\
\text { with or without food }\end{array}$ & No \\
\hline
\end{tabular}

the severity of urticaria, which is a weekly score summing the severity of itching and skin changes. Urticaria severity score (USS) is a valid score for monitoring the seriousness and severity of urticaria. ${ }^{25-27}$ The method of calculating the score is shown in Table 4, modified according to Zuberbier. $^{3}$

There are new guidelines in CSU therapy published by the American Academy of Allergy, Asthma and Immunology (AAAAI) and the European Academy of Allergy and Clinical Immunology (EAACI)/Global Allergy and Asthma European Network (GALEN)/European Dermatology Forum (EDF)/World Allergy Organization (WAO) and several other published guidelines with similar recommendations, including the Canadian. According to the new European guidelines, a stepwise approach is applied in CSU therapy:

Table 4: Urticaria activity score (USS)

\begin{tabular}{|c|c|c|}
\hline Score & Wheal & \\
\hline 0 & none and/or $<10$ wheals & none \\
\hline 1 & $\begin{array}{l}\text { fewer } \\
(10-50 \text { smaller wheals/24 } \mathrm{h} \text { or }<10 \text { large }\end{array}$ & mild \\
\hline 2 & $\begin{array}{l}\text { moderate number } \\
(>50 \text { smaller wheals/24 h) or } 10-50 \text { larger }\end{array}$ & moderate \\
\hline 3 & $\begin{array}{l}\text { intense occurrence of wheals } \\
\text { ( }>50 \text { wheals/ } 24 \mathrm{~h} \text {, generalised occurrence } \\
\text { of wheals }\end{array}$ & intense \\
\hline
\end{tabular}

first-line treatment includes second-generation H1 antihistamines, second-line therapy includes increasing the dose of second-generation $\mathrm{H} 1$ antihistamines and third-line treatment includes a new medication such as omalizumab, which is preferred over cyclosporine. ${ }^{28}$

One of the significant differences in the guidelines is that the AAAAI algorithm uses first-generation antihistamines, unlike the European guidelines, due to their impact on the REM phase of sleep and impairment of cognitive functions. For similar reasons, they do not accept the use of tricyclic antidepressants. Both guidelines allow administration of systemic corticosteroids for 3 to 7 days, as well as the use of cyclosporine in treating refractory forms of chronic urticaria, and $\mathrm{H} 2$ antihistamines only in individual cases, but not as the first-, second- or third-line treatment. The AAAAI guidelines allow adding other second-generation $\mathrm{H} 1$ antihistamines and adding $\mathrm{H} 2$ antagonists, leukotriene receptor antagonists or first-generation $\mathrm{H} 1$ antihistamines at bedtime. In the third step, both guidelines include omalizumab, a recombinant humanised immunoglobulin G1 (IgG1) monoclonal antibody which binds to IgE. In binding IgE, omalizumab inhibits binding of IgE to the high-affinity IgE receptor. ${ }^{29}$ TNF- $\alpha$ antagonists have been reported to be effective in $60 \%$ of 20 patients with CU in a retrospective study, compared with healthy control cases..$^{30}$ 
Autologous serum therapy and/or autologous whole blood therapy (autohaemotherapy) may be effective in patients with a positive ASST test at weekly intervals during six weeks, and even up to 12 weeks, leading to tolerance, desensitisation (hyposensitisation) of patients with chronic urticaria to pro-inflammatory cytokines. ${ }^{31-36}$

\section{Aim}

1. Determine the frequency of positivity of the autologous serum skin test in patients with individual clinical forms of chronic urticaria.

2. Comparative analysis of clinical picture severity and laboratory parameters in patients with autoimmune and idiopathic chronic urticaria.

3. Determine the success rate of autologous blood treatment in patients with a positive ASST test (patients with autoimmune chronic urticaria).

\section{Methods}

The study was conducted at the Skin and Venereal Diseases Clinic of the Republic of Srpska University Clinical Centre, by random selection, after obtaining permission of the Ethics Committee, as a prospective study of 64 patients with chronic spontaneous urticaria (Figure 1), who were made aware of the methodology and objective of the study. They verified their consent by their own signatures. Anamnestic data were collected and patients were subjected to clinical, dermatological examination and autologous serum testing. A sample of their serum was taken at the time of clinical worsening of the disease. Antihistamines and corticosteroids were stopped two days before the test and antidepressants 3 weeks before the test. ${ }^{37}$ The original ASST test implies intradermal injecting (ID) of $0.05 \mathrm{~mL}$ of autologous serum and $0.05 \mathrm{~mL}$ of $0.9 \% \mathrm{NaCl}$ solution, and a histamine prick test $(10 \mathrm{mg} / \mathrm{mL})$, as a positive reference, at a distance of $3 \mathrm{~cm}$ on the skin of the volar aspect of the forearm. The test was read after 30 minutes. The test was positive if erythematoedematous papule was $1.5 \mathrm{~mm}$ larger than the papule at the site of the injected saline solution (Figure 2). Based on the positivity of the autologous serum test, the subjects over 18 years of age were divided into two groups:

1. Group of CU patients with positive ASST test and positive immune parameters in terms of presence of an associated autoimmune disease, ie autoimmune chronic urticaria ACU.

2. Group of CU patients with negative ASST test and negative immune parameters, which was at the same time both the control group and the studied group with idiopathic chronic urticaria (ICU).

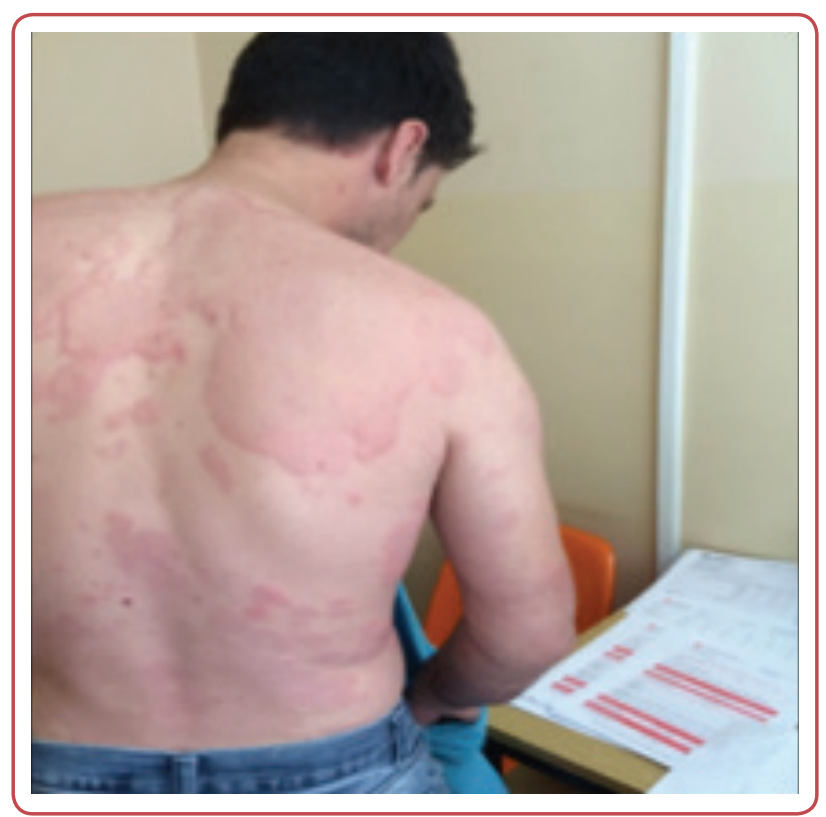

Figure 1: Clinical picture of urticaria (papules, plaques, annular wheals appearance)

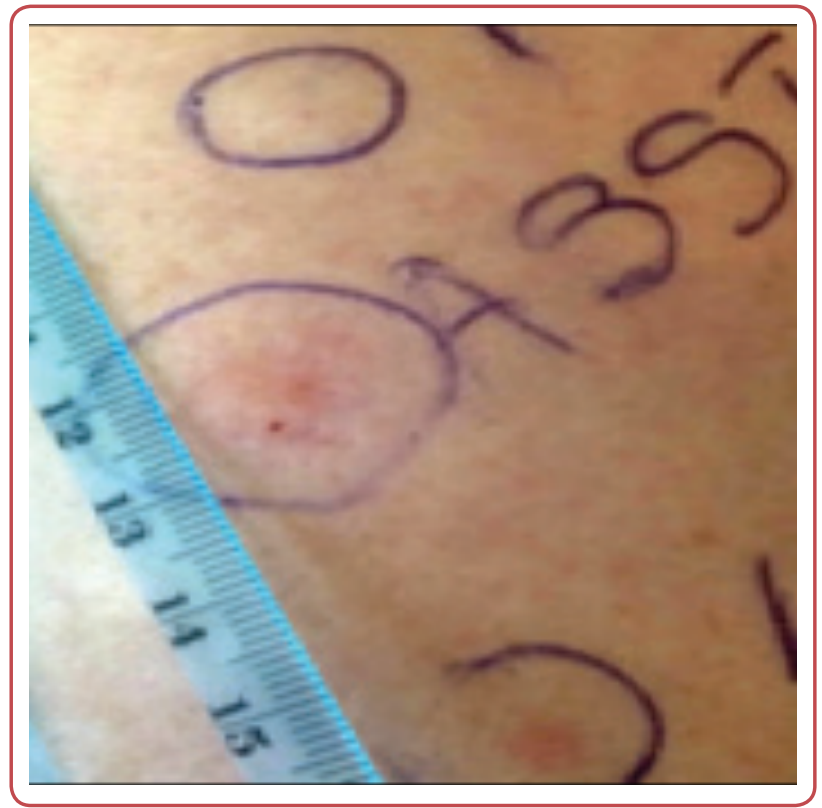

Figure 2: Autologous serum test (ASTT): positive test noted by presence of wheals

The study did not include pregnant women, children or patients with AU. At the beginning of the study, all patients were scheduled to perform the laboratory analyses required in the diagnosis of CU: complement components C3, C4 and ANA, 
Borrelia burgdorferi and Helicobacter pylori serum antibodies, and hepatitis B and C markers. Stool was microscopically examined for parasites and candida. The following laboratory analyses were performed: erythrocyte sedimentation rate (ESR), complete blood count (CBC), routine urine examination, thyroid function test parameters, renal function test and liver enzymes. A prick test with inhalant and nutrient allergens was performed on all patients at the beginning of the study.

As clinical picture of urticaria is variable, self-assessment was performed over 24 hours, using USS. ${ }^{25-27}$ The USS score is the sum of the scores of number of changes and itch intensity. The maximum value of daily USS score may be up to 6 and weekly up to 42 (Table 4). The patients were educated how to calculate the daily score required for calculating the weekly score that was recorded at follow-up examinations. Table 4 shows daily score calculation, modified according to Zuberbier. ${ }^{3}$

The first group of patients received autologous blood therapy, intramuscular (im) injections of 5 $\mathrm{mL}$ of whole blood at weekly intervals, during six weeks, with a non-sedating antihistamine and systemic corticosteroids in the exacerbation phase during 3 to 7 days. Depending on clinical picture severity, the second group of patients was prescribed an antihistamine with systemic corticosteroids therapy in the deteriorating phase during 3-7 days im, an antibiotic and an antifungal drugs according to the findings.

Results of the clinical part of the study based on USS score monitoring during the diagnostics and six weeks of treatment of skin changes in patients with chronic urticaria (CU) were obtained. Laboratory findings and other parameters, such as clinical picture severity measured by USS test, duration of urticaria and occurrence of angio-oedema, presence of autoimmune markers in patients with positive and negative ASST test, as well as effect of administered therapy were compared.

The analytical statistical tool SPSS (Statistical Product and Service Solutions) version 20 for descriptive statistics and statistical methods was used, while Microsoft Excel 2007 was utilised for graphical presentation. All results were presented in numbers, tables, charts and figures. Significance level used was $p=0.05$.

\section{Results}

The sample consisted of 64 patients with chronic urticaria, 20 (31.2\%) men and 44 (68.8\%) women. In the ACU group, there were a total of $28(43.8 \%)$ patients, including $4(6.2 \%)$ males and $24(37.5 \%)$ females. In the ICU group, there were a total of 36 (56.2\%) patients, of which 16 (25\%) were males and 20 (31.2\%) females. Use of the Fisher test in the total population of subjects yielded a highly statistically significant difference $(p<0.001)$ in positive values of the ASST test in the group of CU subjects representing ACU patients (compared to the total number of subjects tested of 64).

The average age of patients with ACU was 46.5, and in patients with ICU it was 49.31. Use of the Mann-Whitney U test did not yield a statistically significant difference in the age of ACU subjects $(\mathrm{N}$ $=28, \mathrm{Md}=48)$ and $\mathrm{ICU}$ subjects $(\mathrm{N}=36, \mathrm{Md}=47, \mathrm{U}$ $=442.50, \mathrm{z}=-0.833, \mathrm{p}=0.405, \mathrm{r}=0.104)$.

\section{Disease duration}

The average duration of urticaria was 20 months (95 \% CI: 13.42 - 26.03) in both groups of subjects (Figure 3). Use of the Mann-Whitney U test did not yield a statistically significant difference in urticaria duration between the subject groups with ACU (N = 28, Md = 6.50) and ICU (N = 36, Md = 12.00); $\mathrm{U}=502.00, \mathrm{z}=-0.027, \mathrm{p}=0,978, \mathrm{r}=0.03$ ).

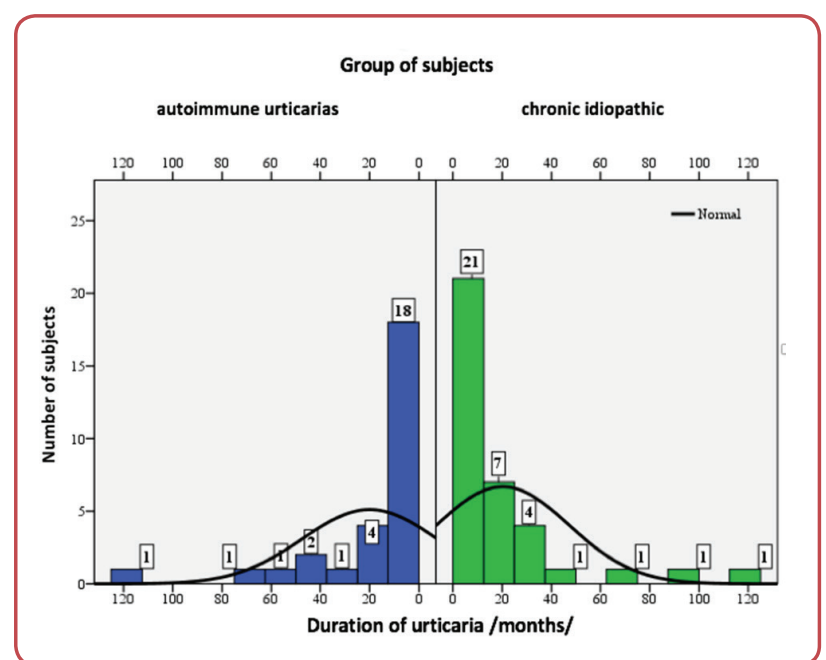

Figure 3: Duration of autoimmune and chronic idiopathic urticaria in weeks

\section{Haematological analysis}

Anaemia was found in $4(14.3 \%)$ patients with ACU, and in $2(5.6 \%)$ patients in the ICU group. Use of the independent samples t-test yielded a statistically significant difference in the incidence 
of anaemia $(t=-2.603, p=0.012)$ in the ACU group of patients compared to the ICU group of patients, while there was no statistically significant difference between the studied groups in the values of other haematological and biochemical findings.

\section{Urine findings}

Urinary tract infection was found in 11 (17.5\%) subjects, as follows: in $3(10.7 \%)$ patients with ACU and 8 (22.9\%) patients with ICU. Use of the Fisher test yielded no statistically significant difference $(p=0.319)$ in urinary tract infection presence between the groups of subjects.

\section{Thyroid function parameters}

TSH reference values were found in 60 (83.8\%) subjects in the total subject population. Only 1 (3.6 $\%)$ patient in the ACU group had hypothyroidism, while $3(4.7 \%)$ patients in the total population of subjects had hyperthyroidism, ie $2(7.1 \%)$ in the ACU group and $1(2.8 \%)$ patient in the ICU group $(p=0.084)$. FT4 reference values were found in $61(95.3 \%)$ subjects in the total population, with no statistical significance by group of subjects $(p=$ $0.284)$. Thyroglobulin antibodies were positive in $5(17.9 \%)$ patients with ACU and in the group of ICU patients, there were no patients with positive antithyroglobulin antibodies. Tissue peroxidase antibodies were positive in $5(17.9 \%)$ patients in the ACU group and in 1 (2.8\%) patient in the ICU group (Figure 4). Use of the Fisher test yielded a statistically significant difference $(p=0.013)$ in the level of thyroglobulin antibody titre in patients with ACU, while use of the above test did not yield a statistically significant difference in the level of tissue peroxidase titre in the total population of subjects $(\mathrm{p}=0.078)$.

\section{Immunological parameters}

ANA were positive only in $1(3.6 \%)$ patient in the total population of subjects, and use of the Fisher

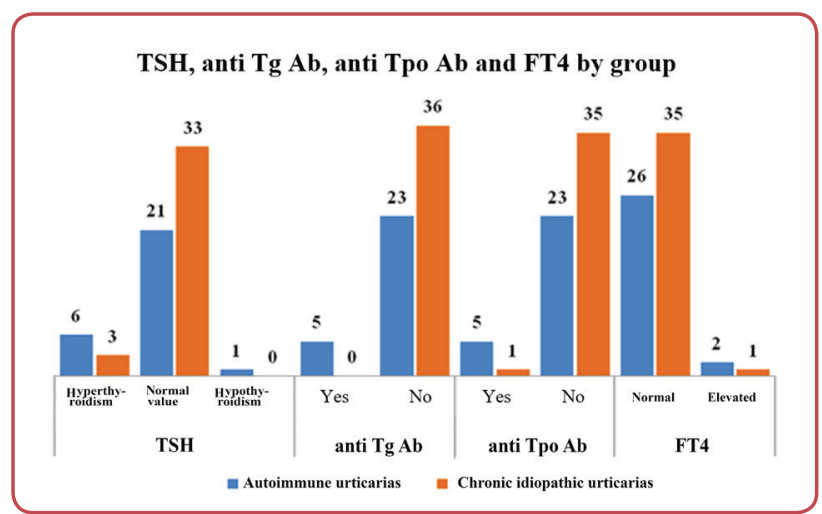

Figure 4: Thyroid gland hormones and anti Tg and anti TPO antibodies in patients with autoimmune and chronic idiopathic urticaria test yielded no statistically significant difference $(p=0.438)$ in ANA values between the groups of subjects. Consumption of complement component C3 was recorded in 5 (7.8) patients, ie in 2 (7.1\%) patients with ACU and $3(8.3 \%)$ patients with ICU. Elevated C3 values were found in $1(2.8 \%)$ patient with ICU, while the complement component was elevated in $2(5.6 \%)$ patients with ICU.

\section{Presence of fungi and parasites}

No parasite eggs or intestinal protozoan cysts were found in stool of any subject from any group at the beginning of the study. Stool candida was isolated in $4(14.3 \%)$ patients with ACU and 11 $(30.6 \%)$ patients in the ICU group, but use of the Fisher test did not yield a statistically significant difference in the number of patients with the isolated candida in stool $(\mathrm{p}=0.149)$.

\section{Test for Helicobacter pylori and Borrelia burgdorferi}

The subjects were tested for Helicobacter pylori at the beginning of the study. Positive values were found in $14(50.0 \%)$ patients in the ACU group and $11(30.6 \%)$ patients in the ICU group. Use of the $\chi^{2}$ test with Yates correction yielded no statistically significant difference $\left(\chi^{2}=1.751, \mathrm{p}=\right.$ 0.186 ) in the positivity of the Helicobacter pylori test by group of subjects, although a larger number of subjects was in the ACU group. Positive IgM antibodies to Borrelia burgdorferi were found in $4(14.3 \%)$ patients with ACU and $3(8.3 \%)$ patients with ICU, while IgG was positive in $3(10.7$ $\%)$ patients with ACU and 1 (2.8\%) patient with ICU (Figure 5).

Use of the Fisher test yielded no statistically significant difference in the values of IgM and IgG antibodies to Borrelia burgdorferi between the groups of subjects: $\operatorname{Ig} M(p=0.689), \operatorname{IgG}(p=0.311)$.

All patients in the ACU and ICU groups had negative hepatitis $B$ and $C$ markers.

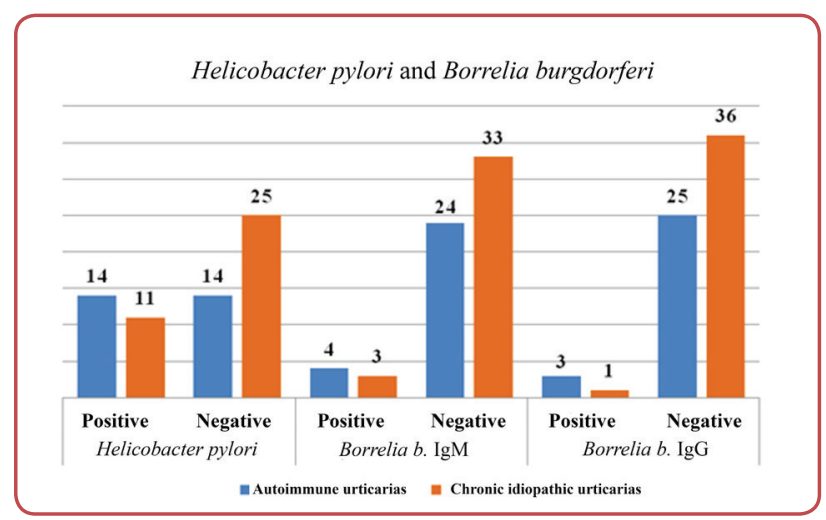

Figure 5: Helicobacter pylori and Borrelia burgdorferi tests in patients with autoimmune and chronic idiopathic urticaria 


\section{Allergy testing}

A prick test with inhalant and nutrient allergens was performed on all patients at the beginning of the study. The prick test with nutrient allergens was negative in all subjects, while the one with inhalant allergens was positive in $6(21.4 \%)$ patients with ACU and $3(8.3 \%)$ patients with ICU. The most common positive allergens were mixtures of grass, tree and weed pollen, as well as house dust mites. Use of the Fisher test yielded no statistically significant difference $(\mathrm{p}=0.163)$ in prick test positivity between the groups of subjects.

\section{USS score values}

The mean USS value in the ACU patients receiving IM autologous blood therapy at weekly intervals was $23.54 \pm 11.91$ in the first week, and $1.39 \pm$ 2.47 (F $1.13 \pm 2.401$, M $3.00 \pm 2.582$ ) in the sixth week. In ICU patients, USS was $21.67 \pm 11.689$ in the first week and $2.72 \pm 2.835$ (F $3.00 \pm 2.956$, M $2.38 \pm 2.729$ ) in the sixth week (Figure 6 ). Use of the Wilcoxon signed-rank test in monitoring ACU patients yielded a highly statistically significant difference $(z=-4.375, p=0.000)$ in weekly USS in the sixth week compared to the first week, due to the applied autologous blood therapy.

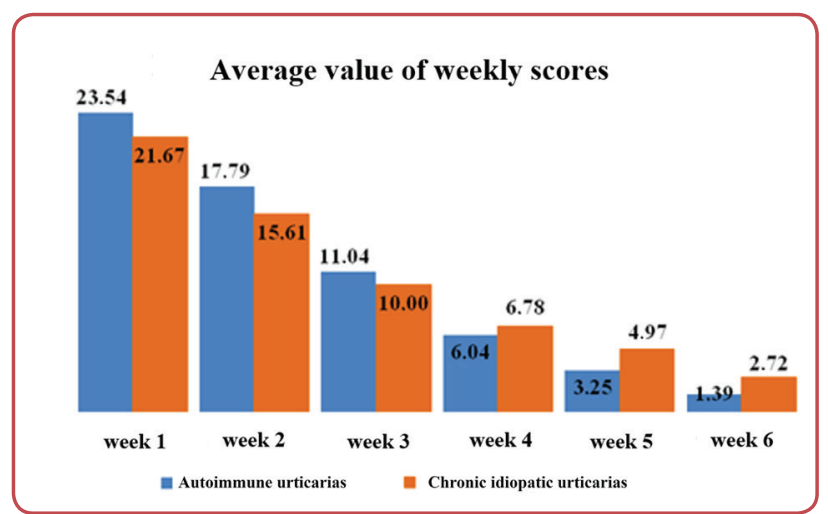

Figure 6: Median weekly values of urticaria severity score (USS)

\section{Applied therapy}

Methylprednisolone in an im $40 \mathrm{mg}$ dose once a day for seven days was prescribed during the exacerbation phase of urticaria in 27 (75\%) patients in the ICU group, and only in 9 patients in the ACU group (in 7 patients who received autologous blood). According to the $\chi^{2}$ test with Yates correction $\left(\chi^{2}=10.078, p=0.002\right)$, this difference in the need for methylprednisolone therapy is highly statistically significant by group of subjects.

In patients with ICU, there was no statistically significant difference in weekly USS in the first (U $=126,000, \mathrm{z}=-0.612, \mathrm{p}=0.558$ ) and in the sixth week $(U=136.000, z=-0.299, p=0.788)$ by group of subjects. The use of methylprednisolone did not affect much the therapeutic response in patients with ACU and ICU, so remission was achieved mainly due to the use of autologous blood in the ACU group, and other conventional therapy in the ICU group.

Antibiotics were prescribed after obtaining of test results (to Helicobacter pylori, Borrelia burgdorferi), or in patients with inflammatory syndrome (accelerated sedimentation, leucocytosis, neutrophilia, thrombocytosis, high value of complement component C4). The antibiotic (azithromycin) was prescribed in $35(54.7 \%)$ patients, ie in 15 (53.6 $\%)$ patients with ACU and 20 (55.6\%) patients with ICU, in addition to other prescribed therapy.

Use of the $\chi^{2}$ test with Yates correction yielded no statistically significant difference $\left(\chi^{2}=0.000, p=\right.$ 1.000 ) in the use of antibiotics in both groups of subjects.

Patients with candida isolated from the stool were prescribed fluconazole (Diflucan ${ }^{\mathrm{R}}$, generic fluconazole) at $150 \mathrm{mg}$ in weekly doses during four weeks in $15(23.4 \%)$ patients, ie $5(7.8 \%)$ patients in the ACU group and $10(15.6 \%)$ patients in the ICU group. No statistically significant difference $(p=0.149)$ in the use of fluconazole between the groups of subjects was yielded by the Fisher test.

\section{Discussion}

In the Te-Peng Tseng study, CU was more common in female population and there was no difference in age groups of the subjects with ACU (40\%) and ICU (22\%), while in the present study it was more common in females. ${ }^{36}$ Urticaria occured in the fifth decade of life in both sexes in this study, and Mozena et al note that ICU occurs more often in women in the third or fourth decade of life, at an average age of $38 \pm 13$ years. ${ }^{38}$ According to Kulthanan, CU mainly affects middle-aged women $(70 \%)$. Chaffari notes that urticaria duration varies from 2 months to 10 years (while in this study it lasted 20 to 26 months) and that urticaria lasts longer in patients with a positive ASST test. George et al compared clinical forms of ACU and ICU in 100 patients with CU, and noted that ACU patients had no special diagnostic, clinical or his- 
topathological features compared to ICU patients, although they tend to have a more severe clinical picture of urticaria. ${ }^{39-41}$

Vohra et al specify the exact methodology and interpretation of ASST and Al-Hamamy et al note ASST as a diagnostic tool in ACU diagnosis. Twenty-two (40.7\%) patients had a positive ASST test and statistical analysis of clinical variables did not show a significant difference between the patients with positive and negative ASST, except for the distribution of wheals $(p=0.004)$. Krupashankar et al deem that positive ASST is a way to select patients with ACU and to start immunomodulatory therapy faster. ${ }^{42-44}$

In the sixth week, the Mann-Whitney test established a statistically significant difference in weekly USS between the studied groups $(\mathrm{U}=357.00$; $\mathrm{z}$ $=-2.138 ; p=0.032$ ) in favour of ACU in our subjects and a lower USS in patients with ACU. Jariwala et al state that USS is a sensitive method, a valid and reliable instrument for monitoring the severity of urticaria and similar results were reported by Mathias and Jáuregui et al, as well. ${ }^{25,26,45}$

Positive values of the Helicobacter pylori test in subjects who participated in the present study were found in $14(50.0 \%)$ patients in the ACU group and $11(30.6 \%)$ patients in the ICU group. Yadav et al note a significant connection between HP infection and HP eradication response in patients with CIU. HP infection should be included in the diagnostic treatment of patients with CIU. Federman suggests conducting HP testing and applying appropriate antibiotic therapy. Moreira et al showed that the prevalence of HP infection in CIU patients was 71.4 $\%$ in the study of $21 \mathrm{CU}$ patients. ${ }^{46-48}$ Research by some authors established association of Borrelia burgdoferi infection with several dermatoses. Warren et al note the occurrence of urticaria associated with Borrelia burgdoferi infection. ${ }^{49}$

Staubach et al state that further research should indicate the importance of fungal infection in CU, especially the importance of IgE antibodies to candida in the CU patients presenting intestinal colonisation with candida. In their study, Ghaffari noted the necessary laboratory findings in evaluating CU. Ghaffari states that aeroallergens can induce exacerbation of CU and the results showed that hypersensitivity to mites is more common in patients with CU. ${ }^{40,50,51}$

Patients with a positive ASST test received autologous whole blood injections (autohaemotherapy) at weekly intervals in im $5 \mathrm{~mL}$ doses, during eight weeks. In line with other results, Tseng et al note the safety of whole blood therapy and long-term disease control, but also the need for further cohort (control) studies on a larger number of patients and a longer follow-up period. ${ }^{36}$

Staubach notes that autologous blood injections in patients with ACU lead to tolerance to histamine-releasing factor in these patients. The patients had satisfactory remission of urticaria, less need for antihistamines and better quality of life, although there was no statistical significance, most likely due to the limited number of patients treated. The results suggest that ASST-positive patients with CU may benefit from autologous whole blood therapy. ${ }^{52-54}$

Federman et al report the effect of antibiotics on CU in patients with a positive HP test. Fukuda et al report complete remission of urticaria in patients with a positive HP test after antibiotic therapy. Kahn notes that the ultimate goal of therapy is to control urticaria, to reduce its impact on the quality of life of patients and negative effects of therapy and to use oral corticosteroids as rarely as possible. ${ }^{47,55,56}$

\section{Conclusion}

1. Out of the total number of subjects in this study, 28 (43.8\%) patients with chronic spontaneous urticaria had a positive autologous serum test and 36 (56.2\%) patients have a negative test.

2. The average duration of urticaria in both groups of patients was approximately 20 months.

3. Subjects with ACU had a significantly higher association with autoimmune thyroid diseases. More frequent occurrence of anaemia was noted in patients with ACU compared to the group of patients with ICU.

4. The mean value of USS score as an indicator of disease severity in the first week was not statistically significant in subjects of any group, while in the sixth week a statistically significant difference of weekly USS was established among the studied groups in favour of ACU.

5. The use of autologous blood therapy in patients with ACU is directly related to the improvement of the clinical picture and lower USS score values. 


\section{Acknowledgements}

None.

\section{References}

1. Saini SS. Chronic spontaneous urticaria: etiology and pathogenesis. Immunol Allergy Clin North Am 2014 Feb;34(1):33-52.

2. Lapi F, Cassano N, Pegoraro V, Cataldo N, Heiman F, Cricelli I, et al. Epidemiology of chronic spontaneous urticaria: results from a nationwide, population-based study in Italy. Br J Dermatol 2016 May;174(5):996-1004.

3. Zuberbier T, Aberer W, Asero R, Bindslev-Jensen C, Brzoza Z, Canonica GW, et al. The EAACI/GA(2) LEN/ EDF/WAO Guideline for the definition, classification, diagnosis, and management of urticaria: the 2013 revision and update. Allergy 2014 Jul;69(7):868-87.

4. Criado PR, Criado RFJ, Maruta CW, dos Reis VMS. Chronic urticaria in adults: state-of-the-art in the new millennium. An Bras de Dermatol 2015;90(1):74-89.

5. Broder MS, Raimundo K, Antonova E, Chang E. Resource use and costs in an insured population of patients with chronic idiopathic/spontaneous urticaria. Am J Clin Dermatol 2015;16:313-21.

6. Konstantinou GN, Asero R, Ferrer M, Knol EF, Maurer M, Raap U, et al. EAACI taskforce position paper: evidence for autoimmune urticaria and proposal for defining diagnostic criteria. Allergy 2013 Jan;68(1):27-36.

7. Beck LA, Bernstein JA, Maurer M. A Review of international recommendations for the diagnosis and management of chronic urticaria. Acta Derm Venereol 2017 Feb 8;97(2):149-58.

8. Confino-Cohen R, Chodick G, Shalev V, Leshno M, Kimhi O, Goldberg A. Chronic urticaria and autoimmunity: associations found in a large population study. J Allergy Clin Immunol 2012 May;129(5):1307-13.

9. Wardhana, Datau EA. Chronic autoimmune urticaria. Acta Med Indones 2012 Apr;44(2):165-74.

10. Levy Y, Segal N, Weintrob N, Danon YL. Chronic urticaria: association with thyroid autoimmunity. Arch Dis Child 2003 Jun;88(6):517-9.

11. Greenberger PA. Chronic urticaria: new management options. World Allergy Organ J 2014 Nov 5;7(1):31. doi: 10.1186/1939-4551-7-31.

12. Konstantinou GN, Asero R, Ferrer M, Knol EF, Maurer M, Raap U, et al. EAACI taskforce position paper: evidence for autoimmune urticaria and proposal for defining diagnostic criteria. Allergy 2013 Jan;68(1):27-36.

13. Ferrer M. Immunological events in chronic spontaneous urticaria. Clin Transl Allergy 2015 Aug 25;5:30. doi: 10.1186/s13601-015-0074-7.

14. Costa C, Gonçalo M; GPEU - Grupo Português de Estudos de Urticária. [Diagnostic and therapeutic approach of chronic spontaneous urticaria: recommendations in Portugal]. Acta Med Port 2016 Nov;29(11):763-81. Portuguese.

15. Perera E, Sinclair R. Evaluation, diagnosis and management of chronic urticaria. Aust Fam Physician 2014 Sep;43(9):621-5.

\section{Conflict of interest}

None.

16. Maurer M, Church MK, Gonçalo M, Sussman G, Sánchez-Borges M. Management and treatment of chronic urticaria (CU). J Eur Acad Dermatol Venereol 2015 Jun;29 Suppl 3:16-32.

17. Vestergaard C, Deleuran M. Chronic spontaneous urticaria: latest developments in aetiology, diagnosis and therapy. Ther Adv Chronic Dis 2015 Nov;6(6):304-13.

18. Godse KV. Autologous serum skin test in chronic idiopathic urticaria. Indian J Dermatol Venereol Leprol 2004 Sep-Oct;70(5):283-4.

19. Fusari A, Colangelo C, Bonifazi F, Antonicelli L. The autologous serum skin test in the follow-up of patients with chronic urticaria. Allergy 2005 Feb;60(2):256-8.

20. Boonpiyathad T, Sangasapaviliya A. Autologous serum and plasma skin test to predict 2-year outcome in chronic spontaneous urticaria. Asia Pac Allergy 2016 Oct;6(4):226-35.

21. Curto-Barredo L, Yelamos J, Gimeno R, Mojal S, Pujol RM, Giménez-Arnau A. Basophil activation test identifies the patients with chronic spontaneous urticaria suffering the most active disease. Immun Inflamm Dis 2016 Oct 4;4(4):441-5.

22. Vikramkumar AG, Kuruvila S, Ganguly S. Autologous serum skin test as an indicator of chronic autoimmune urticaria in a tertiary care hospital in South India. Indian Dermatol Online J 2014 Dec;5(Suppl 2):S87-91.

23. Fiebiger E, Maurer D, Holub H, Reininger B, Hartmann G, Woisetschlager M, et al. Serum IgG autoantibodies directed against the alpha chain of Fc epsilon RI: a selective marker and pathogenetic factor for a distinct subset of chronic urticaria patients? J Clin Invest 1995 Dec;96(6):2606-12.

24. Grattan CE, Wallington TB, Warin RP, Kennedy CT, Bradfield JW. A serological mediator in chronic idiopathic urticaria--a clinical, immunological and histological evaluation. Br J Dermatol 1986 May;114(5):583-90.

25. Jariwala SP, Moday H, de Asis ML, Fodeman J, Hudes G, de Vos G, et al. The Urticaria Severity Score: a sensitive questionnaire/index for monitoring response to therapy in patients with chronic urticaria. Ann Allergy Asthma Immunol 2009 Jun;102(6):475-82.

26. Młynek A, Zalewska-Janowska A, Martus P, Staubach $\mathrm{P}$, Zuberbier T, Maurer M. How to assess disease activity in patients with chronic urticaria? Allergy 2008 Jun;63(6):777-80.

27. Mathias SD, Dreskin SC, Kaplan A, Saini SS, Spector S, Rosén KE. Development of a daily diary for patients with chronic idiopathic urticaria. Ann Allergy Asthma Immunol 2010 Aug;105(2):142-8.

28. Moolani Y, Lynde C, Sussman G. Advances in understanding and managing chronic urticaria. F1000Res 2016 Feb 16;5:F1000 Faculty Rev-177. doi: 10.12688/ f1000research.7246.1.

29. Bernstein JA, Lang DM, Khan DA, Craig T, Dreyfus D, 
Hsieh F, et al. The diagnosis and management of acute and chronic urticaria: 2014 update. J Allergy Clin Immunol 2014;133(5):1270-7.

30. Kocatürk E, Maurer M, Metz M, Grattan C. Looking forward to new targeted treatments for chronic spontaneous urticaria. Clin Transl Allergy 2017 Jan 10;7:1. doi: 10.1186/s13601-016-0139-2.

31. Bajaj AK, Saraswat A, Upadhyay A, Damisetty R, Dhar $S$. Autologous serum therapy in chronic urticaria: old wine in a new bottle. Indian J Dermatol Venereol Leprol 2008;74(2):109-13.

32. Kocatürk E, Aktaș S, Türkoğlu Z, Kavala M, Zindanci I, Koc M, et al. Autologous whole blood and autologous serum injections are equally effective as placebo injections in reducing disease activity in patients with chronic spontaneous urticaria: a placebo controlled, randomized, single-blind study. J Dermatolog Treat 2012 Dec;23(6):465-71.

33. Pittler MH, Armstrong NC, Cox A, Collier PM, Hart A, Ernst E. Randomized, double-blind, placebo-controlled trial of autologous blood therapy for atopic dermatitis. Br J Dermatol 2003 Feb;148(2):307-13.

34. Patil S, Sharma N, Godse K. Autologous serum therapy in chronic urticaria. Indian J Dermatol 2013 May;58(3):225-6.

35. Staubach P, Onnen K, Vonend A, Metz M, Siebenhaar F, Tschentscher I, et al. Autologous whole blood injections to patients with chronic urticaria and a positive autologous serum skin test: a placebo-controlled trial. Dermatology 2006;212(2):150-9.

36. Tseng JTP, Lee WR, Lin SS, Hsu CH, Yang HH, Wang KH, et al. Autologous serum skin test and autologous whole blood injections to patients with chronic urticaria: a retrospective analysis. Dermatol Sinica 2009:27(1):2736.

37. Vikramkumar AG, Kuruvila S, Ganguly S. Autologous serum skin test as an indicator of chronic autoimmune urticaria in a tertiary care hospital in South India. Indian Dermatol Online J 2014 Dec;5(Suppl 2):S87-91.

38. Mozena JD, Adrienne Tińana A, Negri J, John W Steinke JW, Borish L. Lack of a role for cross-reacting anti-thyroid antibodies in chronic idiopathic urticaria. J Invest Dermatol 2010;130(7):1860-5.

39. Kulthanan K, Jiamton S, Gorvanich T, Pinkaew S. Autologous serum skin test in chronic idiopathic urticaria: prevalence, correlation and clinical implications. Asian Pac J Allergy Immunol 2006 Dec;24(4):201-6.

40. Ghafari J, Kosarian M, Nazari Z, Nabavi M. Relation between chronic urticaria and thyrpid autoimmunity. J Univ Med Sci 2008;18(63):66-72.

41. George M, Balachandran C, Prabhu S. Chronic idiopathic urticaria: comparison of clinical features with positive autologous serum skin test. Indian J Dermatol Venereol Leprol 2008 Mar-Apr;74(2):105-8.

42. Vohra S, Sharma NL, Mahajan VK. Autologous serum skin test: methodology, interpretation and clinical applications. Indian J Dermatol Venereol Leprol 2009 SepOct;75(5):545-8.
43. Al-Hamamy HR, Hameed AF, Abdulhadi AS. Autologous serum skin test as a diagnostic aid in chronic idiopathic urticaria. ISRN Dermatol 2013 Apr 18;2013:291524. doi: 10.1155/2013/291524.

44. Krupashankar DS, Shashikala K, Madala R. Clinical and investigative assessment of patients with positive versus negative autologous serum skin test: a study of 80 South Indian patients. Indian J Dermatol 2012 Nov;57(6):434-8.

45. Jáuregui I, Ortiz de Frutos FJ, Ferrer M, Giménez-Arnau A, Sastre J, Bartra J, et al. Assessment of severity and quality of life in chronic urticaria. J Invest Allergol Clin Immunol 2014;24(2):80-6.

46. Yadav MK, Rishi JP, Nijawan S. Chronic urticaria and Helicobacter pylori. Indian J Med Sci 2008 Apr;62(4):15762.

47. Federman DG, Kirsner RS, Moriarty JP, Concato J. The effect of antibiotic therapy for patients infected with Helicobacter pylori who have chronic urticaria. J Am Acad Dermatol 2003;49(5):861-4.

48. Moreira A, Rodrigues J, Delgado L, Fonseca J, Vaz M. Is Helicobacter pylori infection associated with chronic idiopathic urticaria? Allergol Immunopathol (Madr) 2003 Jul-Aug;31(4):209-14.

49. Heymann WR, Ellis DL. Borrelia burgdorferi Infections in the United States. J Clin Aesthet Dermatol 2012 Aug;5(8):18-28.

50. Staubach P, Vonend A, Burow G, Metz M, Magerl M, Maurer M. Patients with chronic urticaria exhibit increased rates of sensitisation to Candida albicans, but not to common moulds. Mycoses 2009 Jul;52(4):334-8.

51. Ghaffari J, Mohammadzadeh I, Mahdavi MR. Skin prick test with aeroallergens in patients with chronic urticaria. J Babol Univ Med Sci 2012; 14(2):66-72.

52. Staubach P, Onnen K, Vonend A, Metz M, Siebenhaar F, Tschentscher I, et al. Autologous whole blood injections to patients with chronic urticaria and a positive autologous serum skin test: a placebo-controlled trial. Dermatology 2006;212(2):150-9.

53. Kumar S, Dhillon SS, Brar BK, Singh A. Comparative evaluation of the therapeutic efficacy and safety of injected histaglobulin versus autologous serum therapy in chronic urticaria. J Clin Aesthet Dermatol 2021 Mar;14(3):38-41.

54. Datta A, Chandra S, Saha A, Sil A, Das NK. Exploring the safety and effectiveness of subcutaneous autologous serum therapy versus conventional intramuscular autologous serum therapy in chronic urticaria: An observer-blind, randomized, controlled study. Indian J Dermatol Venereol Leprol 2020 Nov-Dec;86(6):632-42.

55. Fukuda S, Shimoyama T, Umegaki N, Mikami T, Nakano $\mathrm{H}$, Munakata A. Effect of Helicobacter pylori eradication in the treatment of Japanese patients with chronic idiopathic urticaria. J Gastroenterol 2004;39:827-30.

56. Khan DA. Chronic urticaria: diagnosis and management. Allergy Asthma Proc 2008 Sep-Oct;29(5):439-46. 